\title{
The Practice Exploration of English Professional Translation Teaching under Multimedia Assisted
}

\author{
Guangqun $\mathrm{Li}^{1, \text { a }}$ \\ ${ }^{1}$ Hanjiang Normal University, Shiyan, Hubei Province, China \\ a86894830@qq.com
}

Keywords: English teaching, Multimedia Courseware, Design, Research Strategy

\begin{abstract}
Multimedia technology plays an important role in all walks of life at present, in the same way, in the field of education teaching, the use of multimedia technology, the improvement of teaching level but also played a significant role. Based on teaching practice as the starting point, this paper discusses the multimedia in the teaching activities, especially the application of English teaching, discusses the advantages of multimedia technology in teaching and the problems and relevant solutions.
\end{abstract}

\section{Introduction}

Multimedia teaching is based on the theory of information dissemination and the rule of teaching process and method of design, implementation and evaluation of the process of education system, it through the echoism media, the use of the software and the control through the entire teaching process. The modern education thought, teaching not only requires teachers imparting book knowledge to students, but also in the process of teaching book knowledge to students' intelligence development, training of thinking ability, practical ability to improve, that is to improve student's quality in an all-round way as the own value orientation of multimedia teaching [1]. Through the practice of multimedia in English teaching in recent years, I want to talk about the role of multimedia in English teaching experience.

As we know, in the traditional teaching methods, the communication between students and teachers is relatively simple, blunt the blackboard and chalk tend to make teaching activity also appears dull, students' cognitive and accept the effect not beautiful. And modern multimedia teaching has broken the traditional teaching model, it adopts the multimedia equipment will be focused on a variety of teaching media, by teachers according to the requirements of different class type, the flexible use of related media in teaching practice [2]. Multimedia teaching make full use of a variety of audio and video files, attached to make teaching more fun, the students in the teaching has the feeling of immersive, learning excitement by various stimuli.

\section{The advantage of using multimedia in teaching}

Stimulate the learning enthusiasm of the students. The use of multimedia can stimulate students' learning enthusiasm, to a great degree, our people may have such experience, that is learning activity is a emotional participation of rational thinking activity, is accompanied by emotional experience and rational thinking activity. In the traditional teaching model of the blackboard with chalk, single teaching way, it's easy to let the student feel sense of boring, the resulting emotional colors tend to affect students' learning efficiency will affect the teacher's teaching achievement. But in the multimedia teaching, the students through the image, intuitive, vivid, lively characters, graphics, audio and video and other media information, mobilize the visual and auditory function at the same time this also is the best choice for digesting and absorbing the knowledge [3]. Boring English, therefore, in the wonderful video and sweet music accompanied, let a person more easily accepted. That is a lot of classmates can relish in the English original film, for a simple English word material feel dull sense.

To increase the teaching content. The use of multimedia can greatly increase classroom capacity in the traditional teaching mode, teachers of English in the classroom blackboard writing workload is 
very big. Words, phrases, sentences often need a professor by the teacher blackboard writing to the student. In the process of writing blackboard writing, the valuable class time is not to be able to use high efficiency [4]. And in the multimedia teaching mode, teachers use courseware is completed in advance "finished", without the "processing", so that by the click of a mouse instead of chalk "flying", its efficiency is obvious. At present, with the development of multimedia technology, the courseware in a multimedia environment friendly interface, simple operation, this has saved a lot of valuable class time. Especially for the English needs a lot of blackboard writing course, the improvement of the utilization rate of time is very obvious, with the increase of efficiency means that the class information and knowledge capacity expansion.

Highlight the teaching emphasis and difficulty. The use of multimedia can better outstanding teaching important points and break through the teaching difficulties in the traditional teaching mode, the key points and difficulties in the teaching goal of professor entirely by teachers through verbal and written communication, personal due to restricted by way of simplification, students' cognitive level cannot be guaranteed for knowledge, and modern multimedia teaching can better solve this problem [5]. The use of $2 \mathrm{~d}$ and $3 \mathrm{~d}$ animation technology and video technology, make the abstract and profound knowledge information simplification, visualizations, shortens the distance between students and objective physical, decomposition of the complexity of knowledge information, also shortened the knowledge information from image to abstraction, in the student mind again from abstraction to image processing, fully convey the teaching intention, highlight the teaching focus, so as to maximize the guarantee of the realization of teaching goals.

Teaching information sharing. The use of multimedia network can play the advantage of network information sharing function. Through multimedia network teaching, the students can directly facing the world information platform, collect the necessary learning materials. The United Nations educational, scientific and cultural organization put forward the content of the four pillars of education in the 21st century is: a new generation to learn knowledge, learn to do things, learn to live, learn to live together [6]. Today's a consensus is: the level of an individual in the new century development increasingly depends on the ability to quickly obtain the use of information and the ability of self learning, self education. Multimedia network teaching can promote the cultivation of the students' ability to access information, arouse students' curiosity, and cultivate their correct information from vast network's ability to appropriate screening of useful information. Teachers in the process, the role of relevant teaching content is the student to obtain network information managers, organizers and study partner [6].

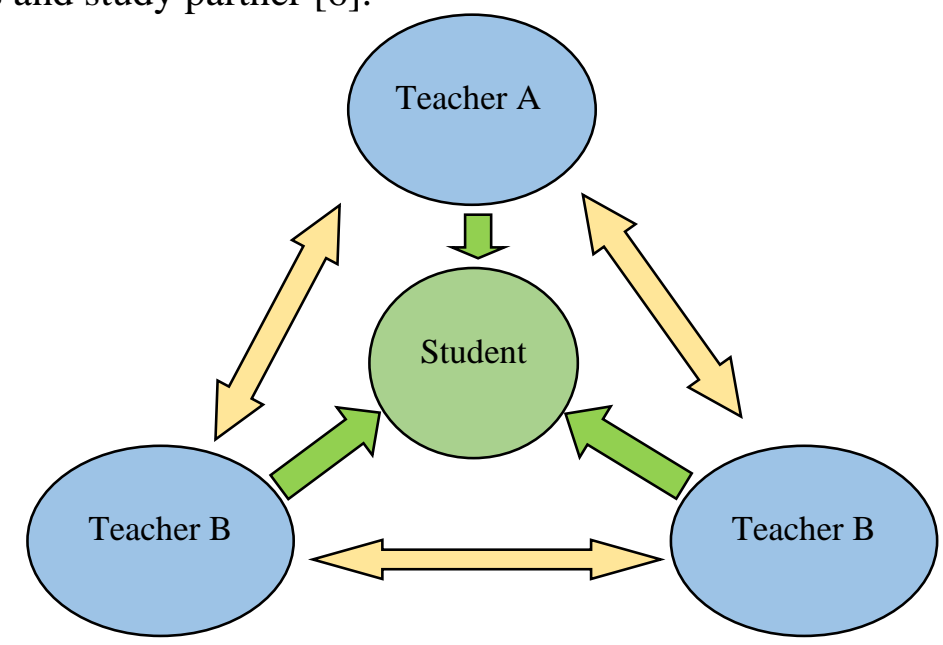

Fig. 1 Information sharing model

Provide real-time and non-real-time communication. The application of multimedia network can provide real-time and non-real-time communication on English learning. Cooperative learning by answering questions. Many students like network chat, the teacher can use the multimedia network teaching platform, cater to students like online chatting mentality, lead into the health English chatroom, use English to communicate with others. Communicate in English in a chat room, can have 
plain text and voice form. Teachers for the text communication and voice communication, decorate different tasks [5].

\section{Virtual reality technology in the application of the courseware}

Now in the market can realize multimedia software has been developed to dozens of, like cult3D, shockwave3D, Fluid3D, virtools, etc. Wide application of cult3D, it can make ordinary users see past can only be seen in the high-end workstations fine real-time rendering effects, can even be completely without hardware acceleration for normal use.

\section{Case 1}

Before I search in the Internet a lot of adverbial clauses of courseware, discovered that a courseware is very comprehensive sums up 9 kinds of adverbial clauses, also equipped with detailed practice, a total of 102 slides. So immediately download and prepare well to introduce students to adverbial clause, let them fully master the grammar. I inform the students in class to the multimedia room in class, students are very excited [6]. (I have arranged a week last multimedia English class at ordinary times, online hearing, video teaching, and form is rich, is popular with students.) Considering the content is more, a class I will say: "Today, We'll study some important grammar, let's begin." students "oh" a cry, feel a little unhappy, quiet down. (Usually a class I will let them listen to listen to the English children's songs, stories or take a look at the flash.) I also didn't pay too much attention, unlock, and send the courseware. When students received after, I immediately began to explain. First click on the slide, the definition of adverbial clause. Because there's no point to this text, I again to let the students read it again. Then ask: "Do you know any kind of Adverbial clause?" There are some students answer: "an adverbial clause of time, place adverbial clauses, adverbial clauses..." "The answer is not comprehensive, think again?" Students have little reaction at this moment, I'll have to let them see the classification of the slide. Below is the teaching important points: the keywords and the application of all kinds of adverbial clauses. Basic teaching carried out in accordance with the same program, such as: "the time adverbial of correlative have?" Student name some, but not all. Let they look at the slide tip, textbook has no associated word, and you can remember it; "We want to pay attention to the relative term when an adverbial clause of time, while, the as..." Then one by one example [7]. After that the two types of adverbial clauses, I found no response about the following students, some students still at my desk, only I'm thirsty, the interpretation of chatter. I'm a little annoyed, intended for students who inattention examples from time to time stood up to read. But it has no substantial change, classroom atmosphere is very dull. Quick class is over, there are two kinds of adverbial clauses before, I had to helplessly to let the students after class to teach yourself. Students during recess as ban, suddenly rushed out of the classroom, I felt a little depressed.

That means: this lesson can be said to be failed, I before starting point is to through the multimedia teaching to expand capacity, improve teaching efficiency. And the actual effect is opposite. Touch problems made me reflect on: the teaching content and students' actual learning have larger in and out? The present and organization form of multimedia teaching can diversify again? So, I on the basis of the original courseware to reschedule the teaching content, design the teaching process.

\section{Case 2}

1) Import set situation teaching style with the adverbial clause grammar teaching, the students in the class in the afternoon mental state is not so good. I opened the "elf" website broadcasting English nursery rhymes "Apple", and lively melody, simple lyrics, immediately aroused the interest of the preschool teacher students [8]. Soon students consciously with singing, don't doze off. After the team performance, conveniently let them I made a sentence with "apple", see who the sentence correct words. Pick some sentences: a. I like eating apples'. b. Don 't eat apples at class; c. I like eating apples when I was young. By observing the students intuitive understanding of adverbial, function and difference of adverbial clause. Very natural transition to the adverbial clause, to learn and understand its definition [8].

That means: import plays an important role in classroom teaching, the "chop wood and whet knife work", to make the students' attention to the import on the contents of teaching. Import well can make the students on the psychological and intellectual ready to learn, to enter the good study condition, 
and stimulate students' interest in learning and seeking knowledge desire, to focus on learning new content. If present new knowledge method, dull, plain, machine-made, students can produce boredom. Therefore, the import of English classroom teaching is a teaching link that nots allow to ignore.

\section{Summary}

With the arrival of information age quickly, it can be said that the multimedia technology is a dynamic in the field of technology, the application of English education in the future has great potential. However, there are many unsolved theoretical problems and has yet to overcome technical barriers. And currently used mainly in the electronic commerce also, games and entertainment, etc., how as soon as possible, as a kind of modern teaching courseware, introduced new technology, and expand its application, there are a lot of work to do. Multimedia itself, of course, the technical requirements, with the relevant design staff, designers, $3 \mathrm{~d}$ design quality etc. All these problems will be bothering this new technology in the application of courseware, which requires us to learn, to think about.

In a word, with the development of computer information technology, multimedia teaching is walked into the classroom, build up the new teaching mode. The application of modern education technology can fully mobilize the students' subjectivity, improve teaching efficiency. We should give full play to the function of multimedia teaching, improve the efficiency of English teaching and the teaching effect.

\section{References}

[1] J.S. Zhang, M.K. Chen, The application of multimedia technology in teaching research, Chinese business, vol.32, pp.66-70, 2008.

[2] S.X. Lu, The Chinese translation teaching research, Shanghai: Shanghai foreign language education press, vol.9, pp.18-22, 1999.

[3] T. T Jun, C. Xia, The application and development of virtual reality technology, Computer Knowledge and Technology, vol.32, pp. 3-7, 2008.

[4] S.L. Wang, Q.Y. Wu, Virtual experiments conducted systematic research and application of Computer, Engineering and Science, vol.22, pp.22-24, 2000.

[5] J. Jiang, M.K. Chen, Virtual Reality Technology in Experimental Teaching in Higher Vocational Studies, Chinese business, vol.6, pp.43-47, 2008.

[6] X.F.Lei, X.J. Li, Design principles English Multimedia Courseware, Academia (monthly), vol.11, pp.61-67, 2010.

[7] T.Y Wang, Multimedia Teaching of English usage, Chinese Science and Technology Expo, vol.7, pp.87-91, 2010.

[8] S.X. Zeng, The important role of multimedia courseware in English Classroom Teaching, Hotan Teachers College (Chinese language Comprehensive Edition), vol.3, pp.11-14, 2008. 